\title{
Model Order Reduction by Routh Stability Array with Stability Equation Method for SISO and MIMO Systems
}

\author{
D. K. Sambariya*, A. S. Rajawat \\ Department of Electrical Engineering, Rajasthan Technical University, Kota, 324010, India
}

Copyright (C)2016 by authors, all rights reserved. Authors agree that this article remains permanently

open access under the terms of the Creative Commons Attribution License 4.0 International License

\begin{abstract}
In this paper, the technique applicable to reduce a high-order system to a low-order system is presented. The methods used are Routh stability array (RSA) method and stability equation (SE) method to get the reduced model of systems. The application of the techniques is examined over SISO linear time invariant systems and extended to MIMO systems. The step response performance of the reduced models gets compared to the original system as well as reduced models in literature in terms of rise-time, settling-time, peak-time and peak of the system. The comparative study reveals that the performances of the reduced models using proposed RSA and SE methods are encouraging as compared to that of with reduced models in literature.
\end{abstract}

Keywords Linear Time Invariant (LTI), Model Order Reduction (MOR), Single-Input Single-output (SISO) System, Multi-input Multi-output (MIMO), Routh Stability Array (RSA) Method, Stability Equation (SE) Method, High-order System (HOS)

\section{Introduction}

Nowadays, system becomes very complicated, tedious \& costly by increases the use of some external controlling devices and the calculation, complexity, cost becomes major factor and also creates a problem for analyst or programmer to solve those high-order system (HOS) problems [1, 2]. The dynamic stable systems with least cost, minimum complexity, better characteristics, ease in operation, and low time computation requirements are known as the most economical system. Several techniques have been considered for reduction of high-order LTI models into the lower-order models to reduced system complexity, cost-effectiveness as compared to the original system [3].
All the control system and power system networks defined in MATLAB using a block diagram in SIMULINK portion may represent a higher-order transfer function for that system [4]. This transfer function for the simplicity or for ease of operation must be reduced to a lower-order transfer function using a reduction technique prevalent in literature such as Routh approximation [5], Pade approximation [6], Routh-Pade method $[7,8]$, Stability equation method [9, 10, 11, 12], Differentiation method $[2,3,4,13]$, Routh Stability array method [10, 14], pole clustering [15], integral square error method [1] and/or based on soft computing techniques such as genetic algorithm (GA) [16, 17], particle swarm optimization (PSO) [18, 19], bat algorithm (BA)[1] and Harmony search algorithm [7] etc.

In Routh approximation, the reciprocals of the coefficients for both numerator and denominator polynomial's alpha (for denominator) and beta (for numerator) tables. The reduced order model is determined and reconsidered for reciprocal of their coefficients to calculate final decreased model using Routh approximation method [20]. In differentiation method, the first reciprocal coefficients are determined for both numerator and denominator polynomials until the desired reduced model is obtained [4]. The application of model order reduction techniques have been considered for reduction of single-machine infinite-bus (SMIB) power system in $[21,20,10,22,23]$.

The Routh stability array method is based on array method, in which; array for numerator and denominator polynomials are derived. In stability equation method, the reduced models with a successively elimination of two high-order elements in each step are obtained to get the low order system [10]. In Sambariya 2016 [24], the mixed application of Routh approximation method and cuckoo search algorithm is presented. The SMIB power system is reduced using stability equation method and self adaptive bat algorithm is presented in [25]. The application of Routh stability array method is presented in [26]. 
In this paper, a mixed technique is used for deduction of the high-order problem to lower order model 2nd or 3rd order system. The reduction topologies are considered in order to make the hybrid technique. These are Routh Stability Array (RSA) [27], and Stability Equation methods are considered. The numerator of the system is reduced using RSA method, while the denominator is reduced using SE method. As an example, four problems are considered with three on single-input single-output (SISO) and one on multiinput multi-output (MIMO) systems.

The rest of paper is arranged within fix sections. Problem formulation in shows in section 2. Detailed description of RSA-MOR described in section 3. Description of stability equation method explained in section 4. All four examples on SISO and MIMO systems are explained in section 5 . It includes the comparative study of the reduced systems in literature and that of with proposed methods. Finally the paper is concluded in section 6 followed by references.

\section{Problem formulation}

Let an $n^{t h}$ high-order transfer function $G(s)$ given below in Eq. 1.

$$
G(s)=\frac{\sum_{i=0}^{n-1} a_{i} s^{i}}{\sum_{i=0}^{n} b_{i} s^{i}}
$$

where,

- $G(s)$; indicates a $n^{\text {th }}$ high-order system,

- $a_{i} \& b_{i}$; indicates scalar constants of original transfer function

This high order transfer function is reduced by RSAMOR method of $r^{t h}$ order represented as in Eq. 2 .

$$
R(s)=\frac{\sum_{j=0}^{r-1} c_{j} s^{j}}{\sum_{j=0}^{r} d_{j} s^{j}}
$$

where,

- $\mathrm{R}(\mathrm{s})$; indicates a rth reduced order system,

- $c_{j} \& d_{j}$; indicates scalar constants of reduced order system

This reduced model having maximum properties of original function $G(s)$ for same type of inputs.

\section{Routh Stability Array}

This method uses the generation of Routh array by using coefficients of given $n^{t h}$ high-order polynomial of a problem. First, two rows indicate generated rows, having the coefficients of original HOS. After that all the rows known as computed rows derived from previous
Table 1. Generating Rows

\begin{tabular}{lllll}
\hline$a_{0}$ & $a_{1}$ & $a_{2}$ & $a_{3}$ & $\cdots$ \\
$b_{0}$ & $b_{1}$ & $b_{2}$ & $b_{3}$ & $\cdots$ \\
\hline
\end{tabular}

Table 2. Computing Rows

\begin{tabular}{lllll}
\hline$c_{0}$ & $c_{1}$ & $c_{2}$ & $c_{3}$ & $\ldots$ \\
$d_{0}$ & $d_{1}$ & $d_{2}$ & $d_{3}$ & $\ldots$ \\
\hline
\end{tabular}

two rows [4]. First row of generated rows indicates $1^{\text {st }}$, $3^{r d}, 5^{t h}, \ldots$ order coefficients and second rows indicate $2^{\text {nd }}, 4^{\text {th }}, 6^{\text {th }}, \ldots$ order coefficients. Consider an nth order polynomial HOS $P(s)$ is given below as in Eq. 3

$$
P(s)=a_{0} s^{n}+b_{0} s^{(n-1)}+a_{1} s^{(n-2)}+b_{1} s^{(n-3)}+\cdots
$$

Routh Array method is popular for determining the stability of high order polynomial system.

Above given Table 1, which indicates generated rows easily understandable by Eq. 3, whereas Table 2 indicates computed rows explained below by mathematical procedure used in Eq. 4.

$$
\begin{array}{ll}
c_{0}=\frac{b_{0} a_{1}-a_{0} b_{1}}{b_{0}} & c_{1}=\frac{b_{0} a_{2}-a_{0} b_{2}}{b_{0}} \\
d_{0}=\frac{c_{0} b_{1}-b_{0} c_{1}}{c_{0}} & d_{1}=\frac{c_{0} b_{2}-b_{0} c_{2}}{c_{0}}
\end{array}
$$

where $a_{0}, a_{1}, \cdots$ and $b_{0}, b_{1}, \cdots$ etc. are the coefficients of generated rows of original system and $d_{0}, d_{1}, \cdots$ and $c_{0}, c_{1}, \cdots$ are the coefficients of computed rows derived from just previous two rows.

\subsection{Reduction methodology}

Let the high-order transfer function for a SISO system is shown as in Eq. 5 .

$G(s)=\frac{b_{11} s^{m}+b_{21} s^{(m-1)}+b_{12} s^{(m-2)}+b_{22} s^{(m-3)}+\cdots}{a_{11} s^{n}+a_{21} s^{(n-1)}+a_{12} s^{(n-2)}+a_{22} s^{(n-3)}+\cdots}$

where,

- $G(s)$, indicates HOS transfer function,

- $n$, indicates order of denominator of HOS,

- $m$, indicates order of numerator of HOS

The table for numerator and denominator are derived according to Eq. 5 and is mentioned in Table 3 and Table 4.

Table 3. Routh stability array for numerator

\begin{tabular}{ccccc}
\hline$b_{11}$ & $b_{12}$ & $b_{13}$ & $b_{14}$ & $\ldots$ \\
$b_{21}$ & $b_{22}$ & $b_{23}$ & $b_{24}$ & $\ldots$ \\
$b_{31}$ & $b_{32}$ & $b_{33}$ & $\ldots$ & \\
$b_{41}$ & $b_{42}$ & $b_{43}$ & $\ldots$ & \\
$\vdots$ & $\vdots$ & & & \\
$b_{m-1,1}$ & $\ldots$ & & & \\
$b_{m+1,1}$ & $\ldots$ & & & \\
\hline
\end{tabular}


Table 4. Routh stability array for denominator

\begin{tabular}{ccccc}
\hline$a_{11}$ & $a_{12}$ & $a_{13}$ & $a_{14}$ & $\ldots$ \\
$a_{21}$ & $a_{22}$ & $a_{23}$ & $a_{24}$ & $\ldots$ \\
$a_{31}$ & $a_{32}$ & $a_{33}$ & $\cdots$ & \\
$a_{41}$ & $a_{42}$ & $a_{43}$ & $\ldots$ & \\
$\vdots$ & $\vdots$ & & & \\
$a_{n-1,1}$ & $a_{n-1,2}$ & $\ldots$ & & \\
$a_{n, 1}$ & $\ldots$ & & & \\
\hline
\end{tabular}

The computed rows can be calculated by using following algorithm given as in Eq. 6 .

$$
c_{i j}=c_{i-2, j+2}-\frac{c_{i-2,1} \cdot c_{i-1, j+1}}{c_{i-1,1}}
$$

It holds for $i \geq 3$ and $i \leq \frac{n-1+3}{2}$. In RSA method, if the first two rows known then the reduced model can be calculated by applying algorithm formula for computed rows. The transfer function for $n-1$ reduced system can be calculate by second generated row and first computed rows as in Eq. 7.

$$
G_{n-1}(s)=\frac{b_{21} s^{(m-1)}+b_{31} s^{(m-2)}+b_{22} s^{(m-3)}+\cdots}{a_{21} s^{(m-1)}+a_{31} s^{(m-2)}+a_{22} s^{(m-3)}+\cdots}
$$

The reduced model of required order as $2^{n d}, 3^{r d}, \cdots$, etc. by applying this general formula applied which is given as in Eq. 8.

$$
R_{k}(s)=\frac{b_{m+2-k, 0} s^{(k-1)}+b_{m+3-k, 1} s^{(k-2)}+\cdots}{a_{n+1-k, 1} s^{k}+a_{n+2-k, 1} s^{(k-1)}+\cdots}
$$

\section{$4 \quad$ Stability equation method}

In this method, a general phenomenon is used to construct reduced model of $2^{\text {nd }}$ or $3^{\text {rd }}$ order from given in high order system. Stability equation method is based on elimination of high order terms in each step. Let consider a transfer function having $n^{\text {th }}$ order high order polynomial function which is given below in Eq. 9 .

$$
\begin{gathered}
G(s)=\frac{b_{m} s^{m}+b_{(m-1)} s^{(m-1)}+\ldots+b_{1} s+b_{0}}{a_{n} s^{n}+a_{(n-1)} s^{(n-1)}+\ldots+a_{1} s+a_{0}} \\
G(s)=\frac{N(s)}{D(s)}
\end{gathered}
$$

where, $n \geq m$. In Eq. $10, N(s)$ and $D(s)$ are the numerator, denominator part respectively. Each numerator and denominator portion divided into two parts as even and another is odd. The numerator can be represented in even and odd terms as $N(s)=N_{e}(s)+N_{o}(s)$ and the denominator can be represented as $D(s)=$ $D_{e}(s)+D_{o}(s)$. Therefore, the $G(s)$ can be written as in Eq. 11.

$$
G(s)=\frac{N_{e}(s)+N_{0}(s)}{D_{e}(s)+D_{o}(s)}
$$

The even and odd terms of the polynomial are written as in Eq. 12 and Eq. 13. where,

$$
N_{e}(s)=\sum_{i=0,2,4}^{m} b_{i} s^{i}
$$

$$
N_{o}(s)=\sum_{i=1,3,5}^{m} b_{i} s^{i}
$$

These two equations are known as stability equation of $N(s)$ and $D(s)$. In this method, we reduce a high order polynomial system by successively discarding the least significant factors from $N(s)$ as well as $D(s)$. In each step some unwanted or least significant terms are eliminated which can be understood by using mathematical explanation given below from Eq. 14 - 23 .

$$
\mathrm{D}(\mathrm{s})=\mathrm{D}_{\mathrm{e}}(\mathrm{s})+\mathrm{D}_{\mathrm{o}}(\mathrm{s})
$$

The expression for even and odd parts of the denominator can be written as in Eq. 15 and Eq. 16.

$$
\begin{aligned}
& \mathrm{D}_{\mathrm{e}}(\mathrm{s})=\mathrm{a}_{\mathrm{o}}+\mathrm{a}_{2} s^{2}+\mathrm{a}_{4} s^{4}+\cdots \\
& \mathrm{D}_{\mathrm{o}}(\mathrm{s})=\mathrm{a}_{1}+\mathrm{a}_{3} s^{3}+\mathrm{a}_{5} s^{5}+\cdots
\end{aligned}
$$

These may be written as

$$
\begin{aligned}
& D_{e}(s)=a_{o} \prod_{i=1}^{k_{1}}\left(1+\frac{s^{2}}{z_{i}^{2}}\right) \\
& D_{o}(s)=a_{1} s \prod_{i=1}^{k_{2}}\left(1+\frac{s^{2}}{{p_{i}}^{2}}\right)
\end{aligned}
$$

Where $k_{1}$ and $k_{2}$ are integer parts of $n / 2$ and $(n-2) / 2$, respectively and $z_{1}{ }^{2}<p_{1}{ }^{2}<z_{2}{ }^{2}<p_{2}{ }^{2}$ by discarding the factors with larger magnitude of $z_{i}$ and $p_{i}$, the reduced stability equations of desired order $r$ become as

$$
\begin{aligned}
& D_{e r}(s)=a_{o} \prod_{i=1}^{r_{1}}\left(1+\frac{s^{2}}{z_{i}{ }^{2}}\right) \\
& D_{o r}(s)=a_{1} \prod_{i=1}^{r_{2}}\left(1+\frac{s^{2}}{{p_{i}}^{2}}\right)
\end{aligned}
$$

where, $r_{1}$ and $r_{2}$ are the integer parts of $r / 2$ and $(r-$ $1) / 2$, respectively. The reduced denominator of formed as

$$
\mathrm{D}_{\mathrm{r}}(\mathrm{s})=\mathrm{D}_{\mathrm{er}}(\mathrm{s})+\mathrm{D}_{\text {or }}(\mathrm{s})
$$

The numerator is reduced similarly and we obtain

$$
\mathrm{N}_{\mathrm{r}}(\mathrm{s})=\mathrm{N}_{\mathrm{er}}(\mathrm{s})+\mathrm{N}_{\mathrm{or}}(\mathrm{s})
$$

The reduced order $R(s)$ is given by

$$
R(s)=\frac{N_{e r}(s)+N_{o r}(s)}{D_{o r}(s)+D_{e r}(s)}
$$

\section{$5 \quad$ Illustrative Examples}

In RSA-MOR method, starting two rows indicates generating rows whereas remaining are the computing rows calculated by the formula given previous section in Eq. 6. In first proposed method, RSA-MOR method is applied for both numerator and denominator. In mixed method, RSA applies for numerator whereas denominator solved using SE-MOR method. In this section four examples are considered to show effectiveness of the proposed model order reduction technique. It includes three examples of SISO systems and an extension to MIMO system. 
Table 5. Reduced models in literature for system in Example-1 $[28]$

\begin{tabular}{|c|c|c|}
\hline S. No. & Method & $2^{\text {nd }}$ order reduced model \\
\hline 1 & Desai, 2013 [29] & $\frac{0.7645 s+1.689}{s^{2}+2.591 s+1.689}$ \\
\hline 2 & Pati, 2014 [30] & $\frac{s+24.0096}{s^{2}+27.0096 s+24.0096}$ \\
\hline 3 & Desai, 2013 [31] & $\frac{0.6965 s+0.6858}{s^{2}+1.428 s+0.6858}$ \\
\hline 4 & Philip, 2010 [32] & $\frac{0.9315 s+1.6092}{s^{2}+2.75612 s+1.6092}$ \\
\hline 5 & Parmar, 2007 [17] & $\frac{0.7442575 s+0.6991576}{s^{2}+1.45771 s+0.6997}$ \\
\hline 6 & Chen, $1980[11]$ & $\frac{0.6997(s+1)}{s^{2}+1.45771 s+0.6997}$ \\
\hline 7 & Parmar, 2007 [33] & $\frac{0.6349 s+4}{s^{2}+5 s+4}$ \\
\hline 8 & Mukherji, 1987 [28] & $\frac{0.8000003 s+2}{s^{2}+3 s+2}$ \\
\hline 9 & Lucas, $1983[34]$ & $\frac{0.833 s+2}{s^{2}+3 s+2}$ \\
\hline 10 & Howitt, 1990 [35] & $\frac{0.81796 s+0.78411}{s^{2}+1.64068 s+0.78411}$ \\
\hline 11 & Howitt, 1990 [35] & $\frac{0.76434 s+1.69073}{s^{2}+2.59288 s+1.69073}$ \\
\hline 12 & Shoji,1982 [36] & $\frac{0.7273 s+2.6497}{s^{2}+3.5975 s+2.6497}$ \\
\hline 13 & Singh, $2004[5]$ & $\frac{0.764444 s+1.688910}{s^{2}+2.590980 s+1.688910}$ \\
\hline 14 & Parmar, 2007 [37] & $\frac{0.6667 s+4}{s^{2}+5 s+4}$ \\
\hline 15 & Komarasamy, 2011 [15] & $\frac{0.8 s+2.0004}{s^{2}+3.0004 s+2.0004}$ \\
\hline 16 & Singh, 2012 [38] & $\frac{2.1931 s+4.5714}{s^{2}+4.7618 s+4.5713}$ \\
\hline 17 & Agrawal, 2011 [39] & $\frac{0.74791 s+2.7692}{s^{2}+3.7692 s+2.7692}$ \\
\hline 18 & Vishwakarma, 2008 [40] & $\frac{-0.189762 s+4.5713}{s^{2}+4.76187 s+4.5713}$ \\
\hline 20 & Panda, 2009 [41] & $\frac{2.9319 s+7.8849}{3.8849 s^{2}+11.4839 s+7.8849}$ \\
\hline 21 & Panda, $2009[41]$ & $\frac{5.2054 s+8.989}{3.8849 s^{2}+11.4839 s+7.8849}$ \\
\hline
\end{tabular}

Table 6. Denominator array using Routh stability array method

\begin{tabular}{lccc}
\hline$s^{4}$ & 1 & 35 & 24 \\
$s^{3}$ & 10 & 50 & 0 \\
$s^{2}$ & 30 & 24 & \\
$s^{1}$ & 42 & 0 & \\
$s^{0}$ & 24 & & \\
\hline
\end{tabular}

\subsection{Example-1}

A fourth order SISO system is considered as presented in Eq. 24 [28].

$$
G_{4}(s)=\frac{s^{3}+7 s^{2}+24 s+24}{s^{4}+10 s^{3}+35 s^{2}+50 s+24}
$$

\subsubsection{ROM in literature}

The authors have screened the literature for second order reduced models using different techniques of the system. The reduced models reported in literature are summarized in Table 5.

\subsubsection{Proposed RSA based ROM}

The RSA method applied on given problem shown in Eq. 24, on the basis of Routh stability array for both denominator in Table 6 and numerator in Table 7 computed terms gives the result as shown in Eq. 25.

$$
R_{2}(s)=\frac{20.57143 s+24}{30 s^{2}+42 s+24}
$$

Table 7. Numerator array using Routh stability array method

\begin{tabular}{lcc}
\hline$s^{3}$ & 1 & 24 \\
$s^{2}$ & 7 & 24 \\
$s^{1}$ & 20.57143 & 0 \\
$s^{0}$ & 24 & \\
\hline
\end{tabular}

\subsubsection{Proposed hybrid RSA and SE based ROM}

The prposed method includes use of Routh stability array method for numerator and stability equation method determine the reduced order model. The RSA is used for reduced numerator and SE for reduced denominator. The numerator using RSA is given by Eq. 26 and the denominator using stability equation method is shown in Eq. 27. The reduced second order reduced model is given as in Eq. 28.

$$
\begin{gathered}
N_{r}(s)=20.57143 s+24 \\
D_{r}(s)=35 s^{2}+50 s+24 \\
R_{2}(s)=\frac{N_{r}(S)}{D_{r}(S)}=\frac{20.57143 s+24}{35 s^{2}+50 s+24}
\end{gathered}
$$

\subsubsection{Results and discussion}

The step response of the original system (as in Eq. 24 , reduced order model in literature (as in Table 5) and that of with proposed (as in Eq. 25 and Eq. 28) are compared in terms of rise-time, settling-time, peak-time and peak as enlisted in Table 8 . The step response of these systems are compared in Fig. 1 Fig. 7.

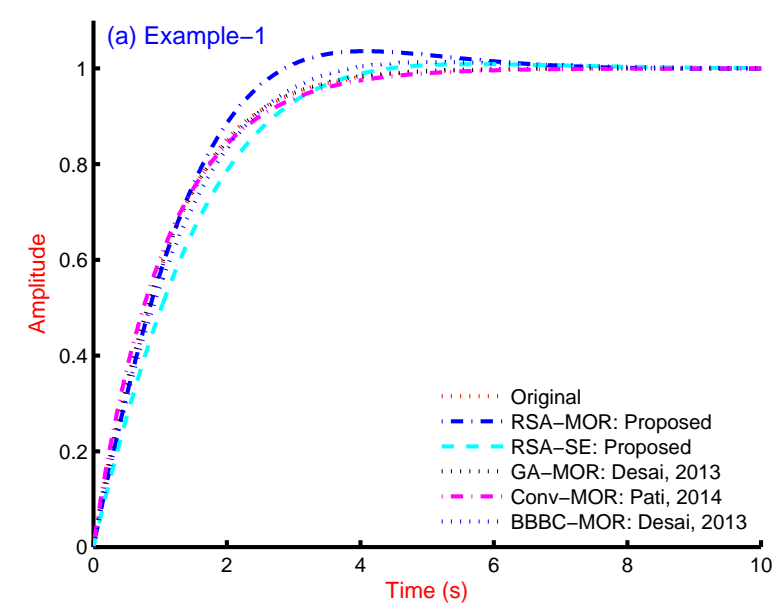

Figure 1. Step response of original system [28], Proposed ROM using RSA (Eq. 25), Proposed ROM using RSA and SE (Eq. 28), MOR in literature such as GA-MOR [29], Conv-MOR [30] and BBBC-MOR [31]

The purpose of comparison is to compare the proposed technique with original to prove similarity of characteristic. These reduced models are also compared with reduced models in literature and found equally good even better in some cases. The considered reduced models in literature are genetic algorithm based GA-MOR [17, 29, 41], conventional technique based Conv-MOR [30], big-bang big-crunch based BBBC-MOR [31, 32], 
Table 8. Comapartive analysis of step response of original system, methods used in literature and proposed models for Example- I

\begin{tabular}{|c|c|c|c|c|}
\hline Method & $\begin{array}{l}\text { Rise } \\
\text { Time (s) }\end{array}$ & $\begin{array}{l}\text { Settling } \\
\text { Time (s) }\end{array}$ & $\begin{array}{l}\text { Peak } \\
\text { Time (s) }\end{array}$ & Peak \\
\hline Original & 2.2602 & 3.9307 & 6.9770 & 0.9991 \\
\hline Proposed RSA & 1.9266 & 5.5869 & 4.0468 & 1.0359 \\
\hline Proposed RSA-SE & 2.5389 & 3.7673 & 5.7285 & 1.0089 \\
\hline Desai, 2013 [29] & 2.2616 & 3.8443 & 9.6778 & 1.0000 \\
\hline Pati, 2014 [30] & 2.3875 & 4.2478 & 8.4934 & 0.9996 \\
\hline Desai, 2013 [31] & 2.2716 & 3.3278 & 5.1430 & 1.0132 \\
\hline Philip, 2010 [32] & 2.5288 & 4.5538 & 9.9334 & 0.9998 \\
\hline Parmar, 2007 [17] & 2.1889 & 3.2202 & 4.9662 & 1.0122 \\
\hline Chen, 1980 [11] & 2.3010 & 3.4111 & 5.2541 & 1.0107 \\
\hline Parmar, 2007 [33] & 2.2694 & 4.0271 & 7.8163 & 0.9995 \\
\hline Mukherji, 1987 [28] & 2.3413 & 4.0916 & 7.8163 & 0.9995 \\
\hline Lucas, 1983 [34] & 2.3199 & 4.0643 & 7.8163 & 0.9995 \\
\hline Howitt, 1990 [35] & 2.2550 & 3.5767 & 5.8832 & 1.0030 \\
\hline Howitt, 1990 [35] & 2.2617 & 3.8449 & 9.6708 & 1.0000 \\
\hline Shoji,1982 [36] & 2.2626 & 3.9618 & 7.5639 & 0.9995 \\
\hline Singh, 2004 [5] & 2.2617 & 3.8446 & 9.6779 & 1.0000 \\
\hline Parmar, 2007 [37] & 2.2645 & 4.0177 & 7.8163 & 0.9996 \\
\hline Komarasamy, 2011 [15] & 2.3413 & 4.0915 & 7.8163 & 0.9995 \\
\hline Singh, 2012 [38] & 1.3117 & 2.5404 & 4.3566 & 0.9983 \\
\hline Agrawal, 2011 [39] & 2.2991 & 4.0453 & 7.8163 & 0.9995 \\
\hline Vishwakarma, 2008 [40] & 1.8370 & 3.3411 & 5.7019 & 0.9991 \\
\hline Panda, 2009 [41] & 2.2687 & 3.9175 & 7.2078 & 0.9994 \\
\hline Panda, 2009 [41] & 1.9442 & 3.5022 & 6.7240 & 1.1393 \\
\hline
\end{tabular}

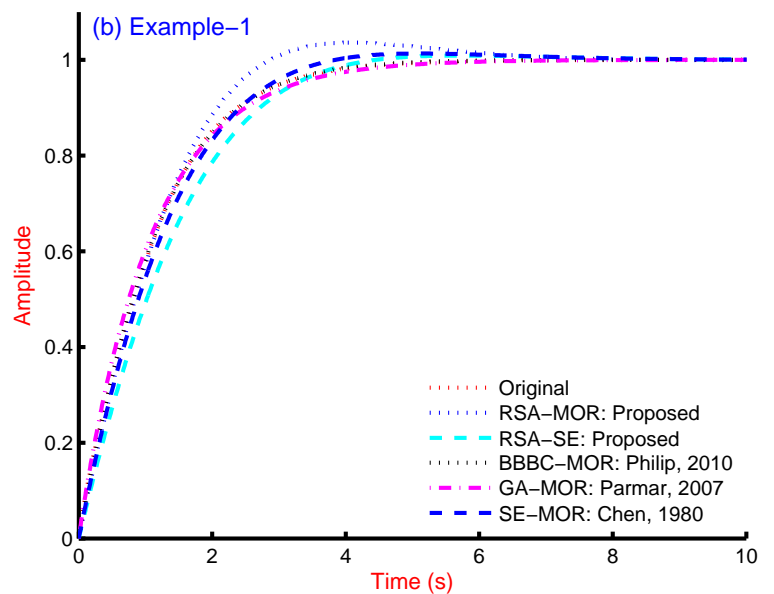

Figure 2. Step response of original system [28], Proposed ROM using RSA (Eq. 25), Proposed ROM using RSA and SE (Eq. 28), MOR in literature such as BBBC-MOR [32], GA-MOR [17] and SE-MOR [11]

stability equation based SE-MOR [11], particle swarm optimization based PSO-MOR [18, 42], error minimization based EMT-MOR [28], factor division based FDMOR [34, 37], integral square minimization based ISEMOR [35, 5], iterative algorithm based Iter-MOR [36], PC-MOR [15, 38, 40], and clustering based Clus-MOR [39].

It could be easy to say that the proposed hybrid method based reduced order model is reflecting early settling to steady state as compared to original system and the RSA based reduced model. The peak value attained by the hybrid method based reduced model is

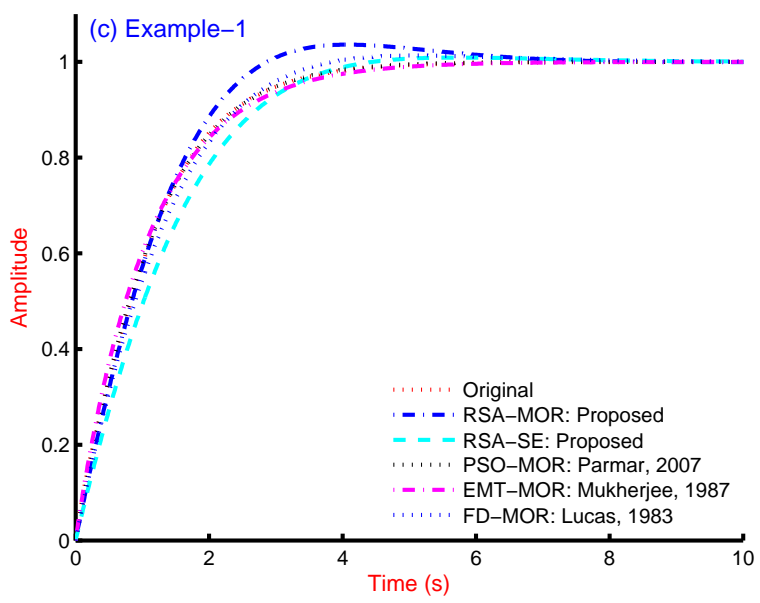

Figure 3. Step response of original system [28], Proposed ROM using RSA (Eq. 25), Proposed ROM using RSA and SE (Eq. 28), MOR in literature such as PSO-MOR [18], EMT-MOR [28] and FD-MOR [34]

lesser as compared to RSA and Original, as well.

\subsection{Example-2}

Considering another 4 th order system as reported in [43] and presented in Eq. 29.

$G_{4}(s)=\frac{4.269 s^{3}+5.10 s^{2}+3.9672 s+0.9567}{4.39992 s^{4}+9.0635 s^{3}+8.021 s^{2}+5.362 s+1}$ 


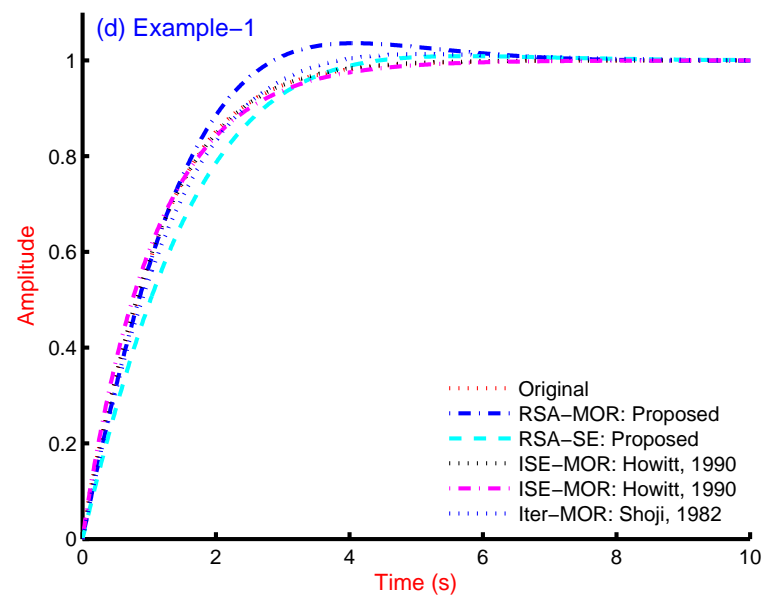

Figure 4. Step response of original system [28], Proposed ROM using RSA (Eq. 25), Proposed ROM using RSA and SE (Eq. 28), MOR in literature such as ISE-MOR [35], ISE-MOR [35] and Iter-MOR [36]

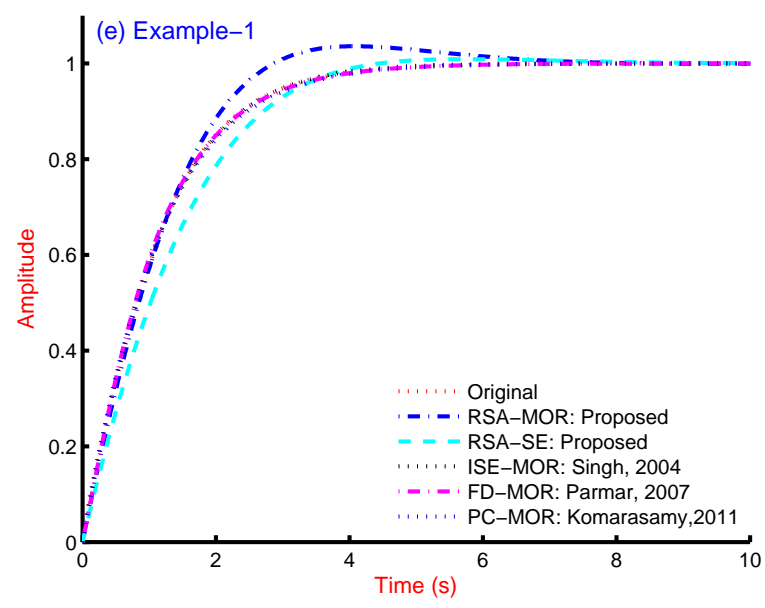

Figure 5. Step response of original system [28], Proposed ROM using RSA (Eq. 25), Proposed ROM using RSA and SE (Eq. 28), MOR in literature such as ISE-MOR [5], FD-MOR [37] and PC-MOR [15]

\subsubsection{ROM in literature}

The $4^{\text {th }}$ order original model of Eq. 29 is solved by different researchers using different techniques of reduction, are summarized in Table 9.

\subsubsection{Proposed RSA based MOR}

The Routh stability array method is used to derive the $2^{\text {nd }}$ order reduced model of the original system. To limit the size of paper, the steps of RSA technique are skipped and the reduced model is presented in Eq. 30.

$$
R_{2}(s)=\frac{3.166386 s+0.9567}{5.417991 s^{2}+3.689147 s+1}
$$

\subsubsection{Proposed hybrid RSA-SE based MOR}

In this method, the numerator of reduced model is solved by RSA as in Eq. 30, while the denominator is

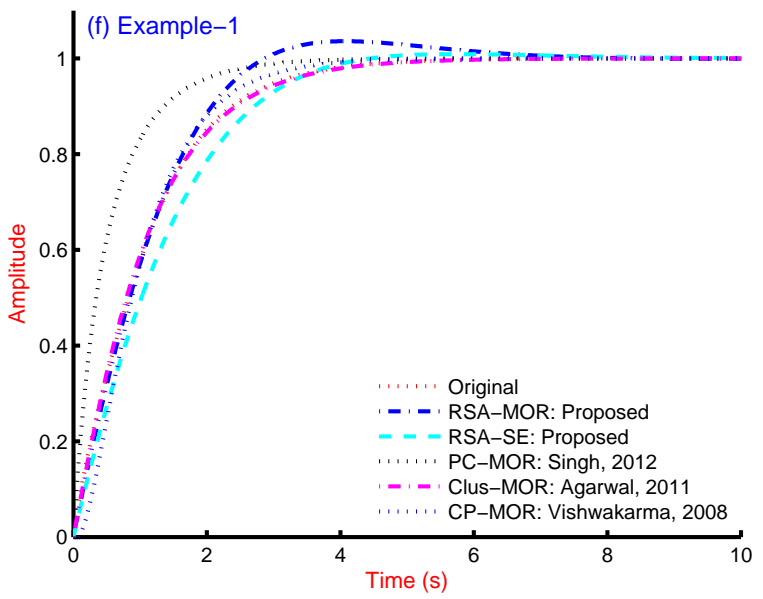

Figure 6. Step response of original system [28], Proposed ROM using RSA (Eq. 25), Proposed ROM using RSA and SE (Eq. 28), MOR in literature such as PC-MOR [38], Clus-MOR [39] and CP-MOR [40]

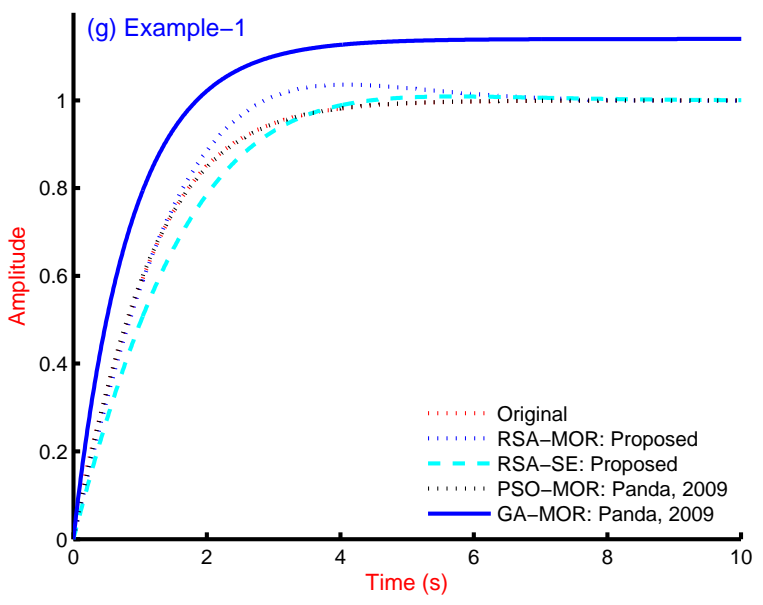

Figure 7. Step response of original system [28], Proposed ROM using RSA (Eq. 25), Proposed ROM using RSA and SE (Eq. 28), MOR in literature such as PSO-MOR [41] and GA-MOR [41]

solved using SE method. The $2^{\text {nd }}$ order reduced model is presented in Eq. 31.

$$
R_{2}(s)=\frac{3.166386 s+0.9567}{8.021 s^{2}+5.362 s+500}
$$

\subsubsection{Results and discussion}

The original system of $4^{t h}$ order is reduced as in previous sections. The step response of the original system of $4^{\text {th }}$ order as in [43] and the reduced $2^{\text {nd }}$ order model in literature [45, 44] are compared with the proposed method based reduced models. The step response comparison is shown in Fig. 8, and the respective step response information in terms of rise time, settling time, peak time and peak are enlisted in Table 10.

The proposed hybrid RSA-SE is appearing again with reduced settling time and peak value as compared to RSA-MOR and the original system. The Aguirre-MOR [45] model is having a large steady state and the settling time as compared to the proposed RSA-SE method. 
Table 10. Comapartive analysis of step response of original system, methods used in literature and proposed models for Example-2

\begin{tabular}{lllll}
\hline Method & Rise & Settling & Peak & Peak \\
& Time (s) & Time (s) & Time & \\
\hline Original [43] & 1.5621 & 9.0437 & 2.8939 & 0.9737 \\
RSA-MOR: Proposed & 2.1766 & 11.7025 & 5.3930 & 1.0882 \\
RSA-SE: Proposed & 4.5437 & 6.9973 & 11.4570 & 0.9650 \\
ABC: Bansal, 2012 [44] & 1.5768 & 2.8456 & 5.3816 & 0.9568 \\
Pade: Bansal, 2012 [44] & 3.1301 & 9.8472 & 18.6056 & 0.9543 \\
Routh: Bansal, 2012 [44] & 2.9087 & 4.3721 & 7.5517 & 0.9741 \\
Aguirre, 1993 [45] & 27.2242 & 48.8617 & 86.0420 & 0.4955 \\
\hline
\end{tabular}

Table 9. The $2^{\text {nd }}$ order reduced models in literature for Example2

\begin{tabular}{cll}
\hline S. No. & Method & $2^{\text {nd }}$ order reduced model \\
\hline 1 & ABC: Bansal,2012 [44] & $\frac{0.2034 s+8.9994}{s^{2}+7.9249 s+9.4008}$ \\
2 & Pade: Bansal,2012 [44] & $\frac{1.869 s+0.5555}{s^{2}+2.663 s+0.5838}$ \\
3 & Routh: Bansal,2012 [44] & $\frac{0.6267 s+0.1511}{s^{2}+0.847 s+0.158}$ \\
4 & Aguirre, $1993[45]$ & $\frac{0.2211 s+0.0702}{s^{2}+1.9531 s+0.1415}$ \\
\hline
\end{tabular}

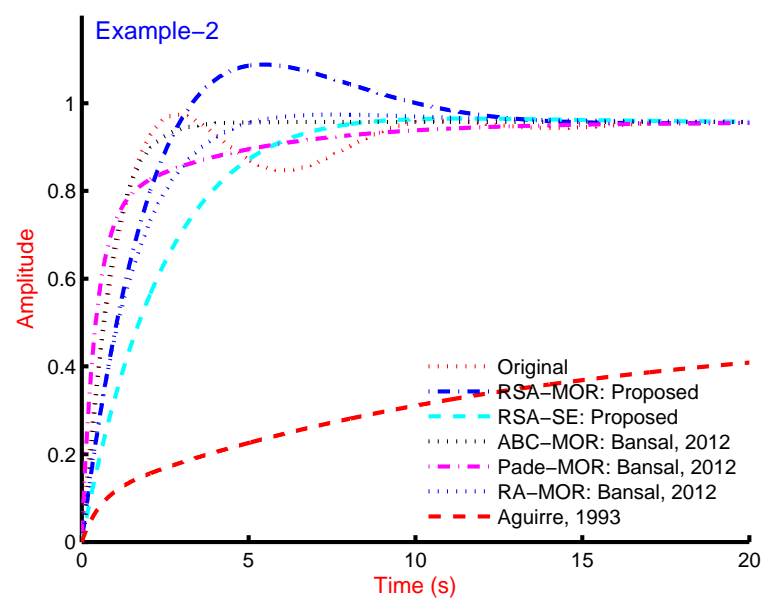

Figure 8. Step response of original system [43], Proposed ROM using RSA, Proposed ROM using RSA and SE, MOR in literature such as ABC-MOR [44], Pade-MOR [44], RA-MOR [44] and Aguirre-MOR [45]

\subsection{Example-3}

Considering another $5^{\text {th }}$ order system as presented in Eq. 32 [46].

$$
G(s)=\frac{10 s^{4}+82 s^{3}+264 s^{2}+396 s+156}{2 s^{5}+21 s^{4}+84 s^{3}+173 s^{2}+148 s+40}
$$

\subsubsection{ROM in literature}

The $5^{\text {th }}$ order original model of Eq. 32 is solved by different researchers using different techniques of reduction, are summarized in Table 11.

\subsubsection{Proposed RSA based MOR}

The Routh stability array method is used to derive the $2^{\text {nd }}$ order reduced model of the original system [46]. To limit the size of paper, the steps of RSA technique are skipped and the reduced model is presented in Eq. 33 .

$$
R_{2}(s)=\frac{336.6974 s+156}{128.1566 s^{2}+123.1151 s+40}
$$

\subsubsection{Proposed hybrid RSA-SE based MOR}

In this method, the numerator of reduced model is solved by RSA as in Eq. 33, while the denominator is solved using SE method. The $2^{\text {nd }}$ order reduced model is presented in Eq. 34.

$$
R_{2}(s)=\frac{336.6974 s+156}{173 s^{2}+148 s+40}
$$

\subsubsection{Results and discussion}

The $5^{\text {th }}$ order problem as in [46], the reduced models in literature as shown in Table 11, and the proposed MOR using RSA and hybrid RSA-SE are compared subjected to step response. The step response comparison is shown in Fig. 9 and the step response information is compared in Table 12. It is found that the proposed method is able to retain original characteristics of the system even with $2^{\text {nd }}$ order reduced model. The rise time with RSA is 2.3065 seconds while that of with original is 2.7457 seconds. The peak time with RSA and RSA-SE are 5.3515 seconds and 7.8459 seconds, respectively and reported as lower as compared to $10.4393 \mathrm{sec}-$ onds with original system. It is again found the RSA-SE method based reduced order is able to quickly settle to steady state with minimum peak as compared to RSA model and the original system.

\subsection{Example-4}

Considering the $6^{\text {th }}$ order multi-input multi-output (MIMO) system as presented in [37, 17]. It is two-input two-output system shown in following Eq. 35.

$$
G(s)=\left[\begin{array}{ll}
\frac{2(s+5)}{(s+1)(s+10)} & \frac{(s+4)}{(s+2)(s+5)} \\
\frac{(s+10)}{(s+1)(s+20)} & \frac{(s+6)}{(s+2)(s+3)}
\end{array}\right]
$$

The common denominator of Eq. 35 is represented by $D(s)$ and presented in Eq. 36 .

$D(s)=s^{6}+41 s^{5}+571 s^{4}+3491 s^{3}+10060 s^{2}+13100 s+6000$

The numerator polynomials are mentioned in Eq. 37 40 .

$N_{11}(s)=2 s^{5}+70 s^{4}+762 s^{3}+3610 s^{2}+7700 s+6000$ 
Model Order Reduction by Routh Stability Array

with Stability Equation Method for SISO and MIMO Systems

Table 11. The $2^{\text {nd }}$ order reduced models in literature for Example-3

\begin{tabular}{cll}
\hline S. No. & Method & $2^{\text {nd }}$ order reduced model \\
\hline 1 & PSO-MOR: Panda, 2009 [46] & $\frac{347.0245 s+225.6039}{135.6805 s^{2}+166.3810 s+57.8472}$ \\
2 & Conv.-MOR: Panda, 2009 [46] & $\frac{369 s+156}{239.5 s^{2}+148 s+40}$ \\
3 & DE-MOR: Yadav, 2011 [47] & $\frac{36 s+156}{93.5606 s^{2}+151.1163 s+39.890}$ \\
4 & Hwang,1996 [48] & $\frac{2.487 s+3.9}{0.4951 s^{2}+1.838 s+1}$ \\
\hline
\end{tabular}

Table 12. Step response information original system, proposed reduced models and the reduced models in literature for example-3

\begin{tabular}{lllll}
\hline Method & $\begin{array}{l}\text { Rise } \\
\text { Time (s) }\end{array}$ & $\begin{array}{l}\text { Settling } \\
\text { Time (s) }\end{array}$ & $\begin{array}{l}\text { Peak } \\
\text { Time (s) }\end{array}$ & Peak \\
\hline Original [46] & 2.7457 & 5.4346 & 10.4393 & 3.8944 \\
RSA: Proposed & 2.3065 & 8.5242 & 5.3515 & 4.0888 \\
RSA-SE: Proposed & 3.4069 & 4.9892 & 7.8459 & 3.9643 \\
PSO: Panda, 2009 [46] & 2.9001 & 4.6323 & 7.7002 & 3.9120 \\
Conv: Panda, 2009 [46] & 3.3484 & 12.4151 & 7.3006 & 4.1744 \\
DE: Yadav, 2011 [47] & 3.3494 & 8.0352 & 17.1344 & 3.9070 \\
Hwang,1996 [48] & 2.9337 & 5.4490 & 9.4668 & 3.8945 \\
\hline
\end{tabular}

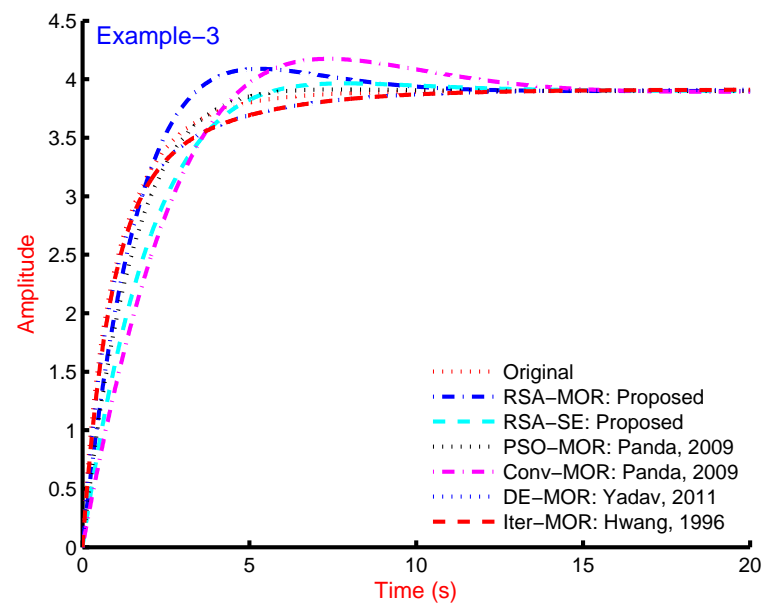

Figure 9. Step response of original system [46], Proposed ROM using RSA, Proposed ROM using RSA and SE, MOR in literature such as PSO-MOR [46], Conv.-MOR [46], DE-MOR [47] and Hwang-MOR [48]

$$
\begin{aligned}
& N_{12}(s)=s^{5}+38 s^{4}+459 s^{3}+2182 s^{2}+4160 s+2400 \\
& N_{21}(s)=s^{5}+30 s^{4}+331 s^{3}+1650 s^{2}+3700 s+3000 \\
& N_{22}(s)=s^{5}+42 s^{4}+601 s^{3}+3660 s^{2}+9100 s+6000
\end{aligned}
$$

Therefore, the original four transfer functions are represented by $G_{i j}=N_{i j} / D_{i j}$. These transfer functions are associated to 2-inputs and 2-outputs.

\subsubsection{ROM in literature}

The above original denominator of the $6^{\text {th }}$ order system as shown in Eq. 36 is subjected to reduce its $2^{\text {nd }}$ order reduced polynomial. Similarly, the four numerator polynomials as shown in Eq. 37 - 40, are subjected to reduce to $2^{\text {nd }}$ order transfer function. These are reduced by different researchers using different techniques and are summarized in Table 13.

\subsubsection{Proposed RSA based MOR}

The $6^{\text {th }}$ order original model of Eq. 35 is solved by Routh stability array method for denominator as well as for four-numerators. The $2^{\text {nd }}$ order reduced model is shown in Eq. 41 and the associated four-numerators are shown in Eq. 42.

$$
\begin{gathered}
D_{r}(s)=7448.008 s^{2}+10443.55 s+6000 \\
N_{r 11}(s)=6121.824 s+6000 \\
N_{r 12}(s)=3559.712 s+2400 \\
N_{r 21}(s)=2942.176 s+3000 \\
N_{r 22}(s)=7904.117 s+6000
\end{gathered}
$$

\subsubsection{Proposed hybrid RSA- SE based MOR}

The original systems denominator is reduced using stability equation method while the four numerators are reduced using Routh stability array method as in Eq. 42. The reduced 2 nd order polynomials are shown in Eq. 43 and the transfer functions are shown in Eq. 44.

$$
\begin{gathered}
D_{r}(s)=10060 s^{2}+13100 s+6000 \\
G_{r 11}(s)=\frac{6121.824 s+6000}{10060 s^{2}+13100 s+6000} \\
G_{r 12}(s)=\frac{3559.712 s+2400}{10060 s^{2}+13100 s+6000} \\
G_{r 21}(s)=\frac{2942.176 s+3000}{10060 s^{2}+13100 s+6000} \\
G_{r 11}(s)=\frac{7904.117 s+6000}{10060 s^{2}+13100 s+6000}
\end{gathered}
$$

\subsubsection{Results and discussion}

In this section, the system with two-inputs and twooutputs is considered. It results to four transfer functions. These transfer functions are denoted by $G_{i j}(s)$ and to be analysized separately. The comparative response of original system, reduced models in literature and the proposed models as $G_{11}(s), G_{12}(s), G_{21}(s)$ and $G_{22}(s)$ are shown in Fig. 10 Fig. 13, respectively and 
Table 13. The $2^{\text {nd }}$ order reduced models in literature for Example- 4

\begin{tabular}{|c|c|c|}
\hline S. No. & Method & Reduced order model \\
\hline 1 & Parmar, 2007 [37] & $\begin{array}{l}D_{r}(s)=s^{2}+13.6666 s+8.4707 \\
r_{11}(s)=6.0429 s+8.4707 \\
r_{12}(s)=3.9419 s+3.3883 \\
r_{21}(s)=2.8097 s+4.2354 \\
r_{22}(s)=8.0195 s+8.4707\end{array}$ \\
\hline 2 & Parmar, 2007 [17] & $\begin{array}{l}D_{r}(s)=s^{2}+1.34952 s+0.6181 \\
r_{11}(s)=0.8503087 s+0.6171331 \\
r_{12}(s)=0.4617562 s+0.2466069 \\
r_{21}(s)=0.4093304 s+0.3086095 \\
r_{22}(s)=0.9976611 s+0.6171125\end{array}$ \\
\hline 3 & Komarasamy, 2011 [15] & $\begin{array}{l}D_{r}(s)=s^{2}+4.0847 s+3.0847 \\
r_{11}(s)=1.30487 s+3.0847 \\
r_{12}(s)=1.0786 s+1.23388 \\
r_{21}(s)=0.5771 s+1.54235 \\
r_{22}(s)=2.0282 s+3.0847\end{array}$ \\
\hline 4 & Vishwakarma, 2009 [49] & $\begin{array}{l}D_{r}(s)=s^{2}+4.3374 s+3.65079 \\
r_{11}(s)=1.18156 s+3.65079 \\
r_{12}(s)=1.04664 s+1.46031 \\
r_{21}(s)=0.49819 s+1.82539 \\
r_{22}(s)=1.6911 s+3.65079\end{array}$ \\
\hline
\end{tabular}

the response data is compared in Table 14 Table 17. The response due to proposed models and that of with original systems are as quite similar in terms of rise time, settling time, peak time and peak. It is also comparative to the systems reduced in literature using different control techniques as presented in [37, 17, 15, 49].

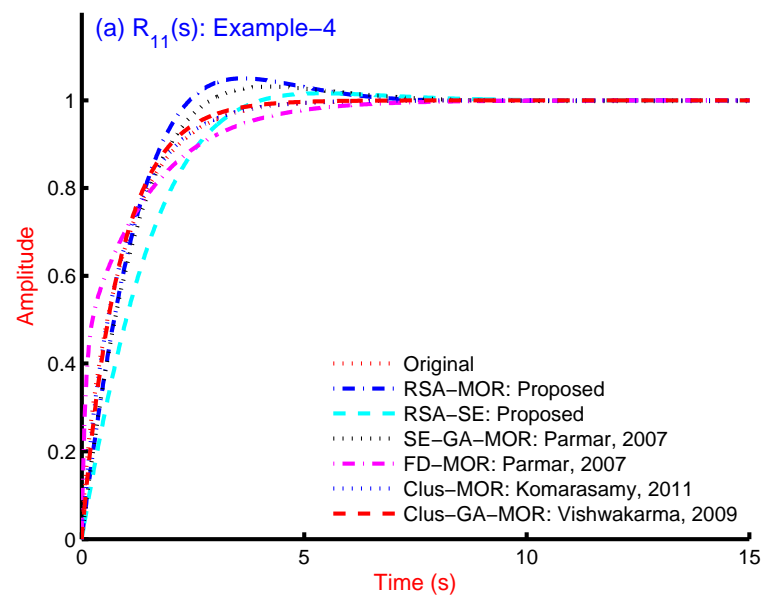

Figure 10. Step response for $G_{11}(s)$ of original system [17], Proposed ROM using RSA, Proposed ROM using RSA and SE, MOR in literature such as $[17,37,15,49]$

The rise time associated to $2^{\text {nd }}$ order reduced model using proposed RSA is 1.6712 seconds, which is lower as compared to original $G_{11}(s)$ and its reduced models in literature. Similarly, for $G_{21}(s)$ and $G_{22}(s)$; the rise time is again lower as 1.7286 and 1.2874 seconds respectively and found to be lesser as compared to orig-

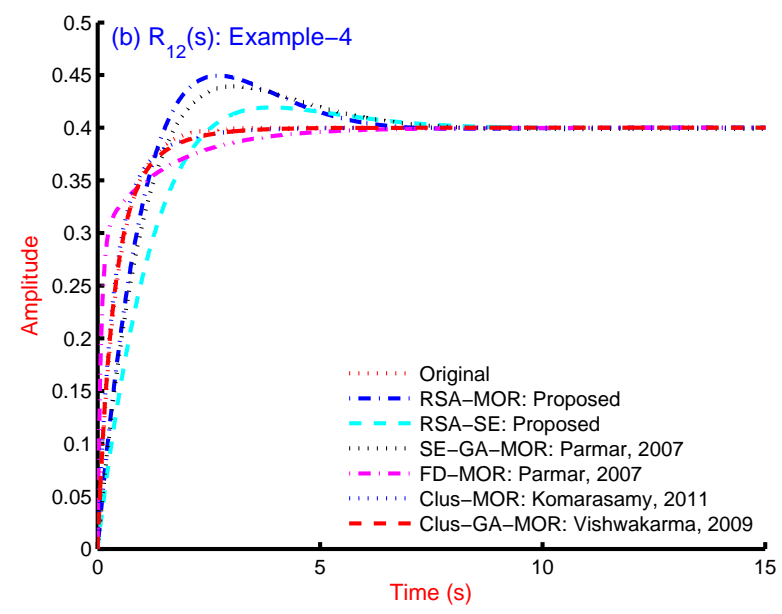

Figure 11. Step response for $G_{12}(s)$ of original system [17], Proposed ROM using RSA, Proposed ROM using RSA and SE, MOR in literature such as $[17,37,15,49]$

inal and reduced models in literature. It is again established while considering the multivariable system that the model with RSA-SE is able to quickly settle as compared to RSA-MOR and original system.

\section{Conclusion}

In this paper, the four different systems have been considered. The three systems are of SISO type and one is considered of MIMO type. These high order systems are reduced to $2^{\text {nd }}$ order model using (i) Routh stability 
Table 14. Comparative analysis of step response of original system, methods used in literature and proposed method of system of Example -4 for $G_{11}(s)$

\begin{tabular}{lllll}
\hline Method & $\begin{array}{l}\text { Rise } \\
\text { Time }(\mathrm{s})\end{array}$ & $\begin{array}{l}\text { Settling } \\
\text { Time }(\mathrm{s})\end{array}$ & $\begin{array}{l}\text { Peak } \\
\text { Time }(\mathrm{s})\end{array}$ & $\begin{array}{l}\text { Peak } \\
\text { Original [17] }\end{array}$ \\
RSA-MOR: Prop. & 2.1254 & 3.7944 & 3.5950 & 0.9998 \\
RSA-SE-MOR: Prop. & 1.6712 & 5.5839 & 5.3982 & 1.0502 \\
SE-GA-MOR: [17] & 2.4575 & 3.5435 & 4.1982 & 1.0161 \\
FD-MOR: [37] & 1.8627 & 5.8176 & 9.4531 & 1.0312 \\
Clust-MOR: [15] & 2.6393 & 5.1309 & 7.2917 & 0.9988 \\
Clust-GA-MOR: [49] & 2.0639 & 3.7543 & 6.8396 & 0.9994 \\
\hline
\end{tabular}

Table 15. Comparative analysis of step response of original system, methods used in literature and proposed method of system of Example -4 for $G_{12}(s)$

\begin{tabular}{lllll}
\hline Method & $\begin{array}{l}\text { Rise } \\
\text { Time }(\mathrm{s})\end{array}$ & $\begin{array}{l}\text { Settling } \\
\text { Time }(\mathrm{s})\end{array}$ & $\begin{array}{l}\text { Peak } \\
\text { Time }(\mathrm{s})\end{array}$ & $\begin{array}{l}\text { Peak } \\
\text { Original [17] }\end{array}$ \\
RSA-MOR: Prop. & 1.0216 & 1.8653 & 3.6459 & 0.3998 \\
RSA-SE-MOR: Prop: & 1.1152 & 5.5910 & 2.6936 & 0.4495 \\
SE-GA-MOR: [17] & 1.7248 & 6.2178 & 3.9479 & 0.4193 \\
FD-MOR: [37] & 1.2438 & 6.3842 & 3.0320 & 0.4394 \\
Clust-MOR: [15] & 1.4314 & 3.9153 & 9.1852 & 0.3997 \\
Clust-GA-MOR: $[49]$ & 0.9931 & 2.2690 & 7.8058 & 0.4000 \\
\hline
\end{tabular}

Table 16. Comparative analysis of step response of original system, methods used in literature and proposed method of system of Example -4 for $G_{21}(s)$

\begin{tabular}{lllll}
\hline Method & $\begin{array}{l}\text { Rise } \\
\text { Time }(\mathrm{s})\end{array}$ & $\begin{array}{l}\text { Settling } \\
\text { Time }(\mathrm{s})\end{array}$ & $\begin{array}{l}\text { Peak } \\
\text { Time }(\mathrm{s})\end{array}$ & $\begin{array}{l}\text { Peak } \\
\text { Original [17] }\end{array}$ \\
RSA-MOR: Prop. & 2.1808 & 3.8582 & 8.8500 & 0.4999 \\
RSA-SE-MOR: Prop. & 1.7286 & 5.5829 & 3.7412 & 0.5232 \\
SE-GA-MOR: [17] & 2.5221 & 3.6481 & 5.5593 & 0.5074 \\
FD-MOR: [37] & 1.9439 & 5.6955 & 4.3537 & 0.5135 \\
Clust-MOR: [15] & 2.7284 & 5.2215 & 8.7117 & 0.4990 \\
Clust-GA-MOR: [49] & 2.1342 & 3.8353 & 8.3409 & 0.4999 \\
\hline
\end{tabular}

Table 17. Comparative analysis of step response of original system, methods used in literature and proposed method of system of Example -4 for $G_{21}(s)$

\begin{tabular}{lllll}
\hline Method & $\begin{array}{l}\text { Rise } \\
\text { Time }(\mathrm{s})\end{array}$ & $\begin{array}{l}\text { Settling } \\
\text { Time }(\mathrm{s})\end{array}$ & $\begin{array}{l}\text { Peak } \\
\text { Time }(\mathrm{s})\end{array}$ & $\begin{array}{l}\text { Peak } \\
\text { Original [17] }\end{array}$ \\
RSA-MOR: Prop. & 1.3378 & 2.2763 & 2.1705 & 0.9995 \\
RSA-SE-MOR: Prop. & 1.2874 & 5.5890 & 1.0914 \\
SE-GA-MOR: [17] & 1.9717 & 5.9957 & 4.4313 & 1.0323 \\
FD-MOR: [37] & 1.5249 & 6.1672 & 3.5762 & 1.0583 \\
Clust-MOR: [15] & 2.1321 & 4.6187 & 8.0567 & 0.9979 \\
Clust-GA-MOR: [49] & 1.6008 & 3.2335 & 6.0968 & 0.9989 \\
\hline
\end{tabular}




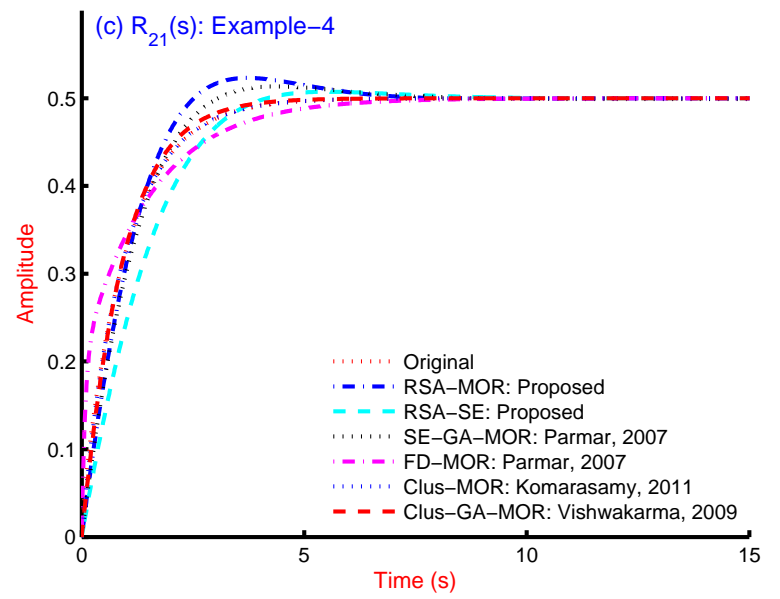

Figure 12. Step response for $G_{21}(s)$ of original system [17], Proposed ROM using RSA, Proposed ROM using RSA and SE, MOR in literature such as $[17,37,15,49]$

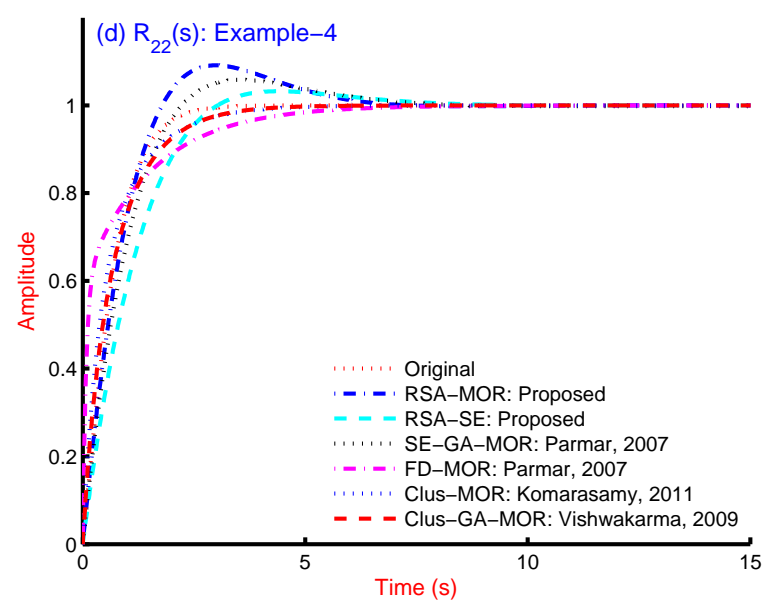

Figure 13. Step response for $G_{22}(s)$ of original system [17], Proposed ROM using RSA, Proposed ROM using RSA and SE, MOR in literature such as $[17,37,15,49]$

array (RSA) method and (ii) the combination of RSA and stability equation (SE) method. The systems reduced order models in literature are considered to compare the response due to proposed RSA based model and proposed RSA-SE based model. The original systems, the respective reduced models of the systems and proposed reduced order models are subjected to step response and its information in terms of rise time, settling time, peak time and peak. The graphical and statistical comparative analysis have been carried out and found to be satisfactory response as compared to original system and reduced models in literature.

\section{REFERENCES}

[1] D. K. Sambariya and H. Manohar, "Model order reduction by integral squared error minimization using bat algorithm," in IEEE Proceedings of 2015 RAECS UIET Panjab University Chandigarh 21-22 ${ }^{\text {nd }}$ December 2015, 2015, pp. 1-7.
[2] D. K. Sambariya and H. Manohar, "Preservation of stability for reduced order model of large scale systems using differentiation method," British Journal of Mathematics \& Computer Science, vol. 13, no. 6, pp. 1-17, 2016. [Online]. Available: http://dx.doi.org/10. 9734/BJMCS/2016/23082

[3] H. Manohar and D. K. Sambariya, "Model order reduction of mimo system using differentiation method," in IEEE Proceeding of $10^{\text {th }}$ International Conference on Intelligent Systems and Control (ISCO 2016), vol. 2, 2016, pp. 347-351.

[4] D. K. Sambariya and H. Manohar, "Model order reduction by differentiation equation method using with routh array method," in IEEE Proceeding of $10^{\text {th }}$ International Conference on Intelligent Systems and Control (ISCO 2016), vol. 2, 2016, pp. 341-346.

[5] V. Singh, D. Chandra, and H. Kar, "Optimal routh approximants through integral squared error minimisation: computer-aided approach," IEE Proceedings Control Theory and Applications, vol. 151, no. 1, pp. 53-58, Jan 2004. [Online]. Available: http://dx.doi. org/10.1049/ip-cta:20040007

[6] I. El-Nahas, N. Sinha, and R. Alden, "Pade and routh approximation in the time domain," in Decision and Control, 1983. The 22nd IEEE Conference on, Dec 1983, pp. 243-246. [Online]. Available: http://dx.doi. org/10.1109/CDC.1983.269837

[7] H. N. Soloklo and M. M. Farsangi, "Multiobjective weighted sum approach model reduction by routh-pade approximation using harmony search," Turk J Elec Eng \& Comp Sci, vol. 21, no. 0, pp. 2283 - 2293, 2013. [Online]. Available: http//dx.doi.org/10.3906/ elk-1112-31

[8] V. Singh, "Obtaining routh-pade approximants using the luus-jaakola algorithm," IEE Proceedings - Control Theory and Applications, vol. 152, no. 2, pp. 129-132, March 2005. [Online]. Available: http://dx.doi.org/10. 1049/ip-cta:20041305

[9] D. K. Sambariya and G. Arvind, "High order diminution of LTI system using stability equation method," British Journal of Mathematics \& Computer Science, vol. 13, no. 5, pp. 1-15, 2016. [Online]. Available: http://dx. doi.org/10.9734/BJMCS/2016/23243

[10] D. K. Sambariya and R. Prasad, "Routh stability array method based reduced model of single machine infinite bus with power system stabilizer," in International Conference on Emerging Trends in Electrical, Communication and Information Technologies (ICECIT-2012), 2012, pp. 27-34.

[11] T. C. Chen, C. Y. Chang, and K. W. Han, "Model reduction using the stability-equation method and the continued-fraction method," International Journal of Control, vol. 32, no. 1, pp. 81-94, 1980. [Online]. Available: http://dx.doi.org/10.1080/ 00207178008922845

[12] D. K. Sambariya and G. Arvind, "Reduced order modelling of SMIB power system using stability equation method and firefly algorithm," in 6th IEEE International Conference on Power Systems, (ICPS-2016), 2016, pp. 1-6.

[13] D. K. Sambariya and R. Prasad, "Differentiation method based stable reduced model of single machine infinite bus system with power system stabilizer," 
International Journal of Applied Engineering Research, vol. 7, no. 11, pp. 2116 - 2120, 2012. [Online]. Available: http://gimt.edu.in/clientFiles/FILE_ REPO/2012/NOV/24/1353741189722/202.pdf.

[14] D. K. Sambariya and A. S. Rajawat, "Application of routh stability array method to reduce MIMO SMIB power system," in 6th IEEE International Conference on Power Systems, (ICPS-2016), 2016, pp. 1-6.

[15] R. Komarasamy, N. Albhonso, and G. Gurusamy, "Order reduction of linear systems with an improved pole clustering," Journal of Vibration and Control, vol. 18, no. 12, p. 18761885, 2011. [Online]. Available: http://dx.doi.org/10.1177/1077546311426592

[16] H. N. Soloklo, O. Nali, and M. M. Farsangi, "Model reduction by hermite polynomials and genetic algorithm," Journal of mathematics and computer science, vol. 9, no. 0, pp. 188-202, 2014.

[17] G. Parmar, S. Mukherjee, and R. Prasad, "Order reduction of linear dynamic systems using stability equation method and ga," International Journal of Computer, Information, and Systems Science, and Engineering, vol. 1, no. 2, pp. 26-32, 2007.

[18] G. Parmar, S. Mukherjee, and R. Prasad, "Reduced order modeling of linear dynamic systems using particle swarm optimized eigen spectrum analysis," International Journal of Computational and Mathematical Science, vol. 1, no. 1, pp. 45-52, 2007.

[19] A. Sikander and R. Prasad, "Soft computing approach for model order reduction of linear time invariant systems," Circuits, Systems, and Signal Processing, vol. 34, no. 11, pp. 3471-3487, 2015. [Online]. Available: http://dx.doi.org/10.1007/s00034-015-0018-4

[20] D. K. Sambariya and R. Prasad, "Routh approximation based stable reduced model of single machine infinite bus system with power system stabilizer," in DRDOCSIR Sponsered: IX Control Instrumentation System Conference (CISCON - 2012), 2012, pp. 85-93.

[21] D. K. Sambariya and R. Prasad, "Stable reduced model of a single machine infinite bus power system with power system stabilizer," in International Conference on Advances in Technology and Engineering (ICATE'13), Jan 2013, pp. 1-10. [Online]. Available: http://dx.doi. org/10.1109/ICAdTE.2013.6524762

[22] D. K. Sambariya and R. Prasad, "Stability equation method based stable reduced model of single machine infinite bus system with power system stabilizer," International Journal of Electronic and Electrical Engineering, vol. 5, no. 2, pp. 101-106, 2012.

[23] D. K. Sambariya and R. Prasad, "Stable reduced model of a single machine infinite bus power system," in 17th National Power Systems Conference (NPSC-2012), 2012, pp. 541-548.

[24] D. K. Sambariya and O. Sharma, "Model order reduction using routh approximation and cuckoo search algorithm," Journal of Automation and Control, vol. 4, no. 1, pp. 1-9, 2016. [Online]. Available: http://pubs. sciepub.com/automation/4/1/1

[25] D. K. Sambariya and G. Arvind, "Reduced order model of single machine infinite bus power system using stability equation method and self-adaptive bat algorithm," Universal Journal of Control and Automation, vol. 4, no. 1, pp. 1-7, 2016. [Online]. Available: http:// dx.doi.org/10.13189/ujca.2016.040101
[26] D. K. Sambariya and A. S. Rajawat, "Model order reduction of lti system using routh stability array method," in IEEE proceedings on International Conference on Computing, Communication and Automation (ICCCA-2016), 2016, pp. 1-6.

[27] V. Krishnamurthy and V. Seshadri, "Model reduction using the routh stability criterion," Automatic Control, IEEE Transactions on, vol. 23, no. 4, pp. 729-731, Aug 1978. [Online]. Available: http://dx.doi.org/10.1109/ TAC.1978.1101805

[28] S. Mukherjee and R. Mishra, "Order reduction of linear systems using an error minimization technique," Journal of the Franklin Institute, vol. 323, no. 1, pp. 23 32, 1987. [Online]. Available: http://www.sciencedirect. com/science/article/pii/0016003287900378

[29] S. R. Desai and R. Prasad, "Implementation of order reduction on tms320c54x processor using genetic algorithm," in Emerging Research Areas and 2013 International Conference on Microelectronics, Communications and Renewable Energy (AICERA/ICMiCR), 2013, pp. 1-6. [Online]. Available: http://dx.doi.org/ 10.1109/AICERA-ICMiCR.2013.6576027

[30] A. Pati, A. Kumar, and D. Chandra, "Suboptimal control using model order reduction," Chinese Journal of Engineering, vol. 2014, p. 5, 2014. [Online]. Available: http://dx.doi.org/10.1155/2014/797581

[31] S. R. Desai and R. Prasad, "A new approach to order reduction using stability equation and big bang big crunch optimization," Systems Science $\&$ Control Engineering, vol. 1, no. 1, pp. 20-27, 2013. [Online]. Available: http://dx.doi.org/10.1080/21642583.2013. 804463

[32] B. Philip and J. Pal, "An evolutionary computation based approach for reduced order modelling of linear systems," in IEEE International Conference on Computational Intelligence and Computing Research (ICCIC '10), 2010, pp. 1-8. [Online]. Available: http:// dx.doi.org/10.1109/iccic.2010.5705729

[33] G. Parmar, S. Mukherjee, and R. Prasad, "Reduced order modeling of linear dynamic systems using particle swarm optimized eigen spectrum analysis," International Journal of Computational and Mathematical Science, vol. 1, no. 1, pp. 45-52, 2007.

[34] T. Lucas, "Factor division: a useful algorithm in model reduction," IEE Proceedings D - Control Theory and Applications, vol. 130, no. 6, pp. 362-364, November 1983. [Online]. Available: http://dx.doi.org/10.1049/ ip-d.1983.0060

[35] G. D. Howitt and R. Luus, "Model reduction by minimization of integral square error performance indices," Journal of the Franklin Institute, vol. 327, no. 3, pp. 343 - 357, 1990. [Online]. Available: http://www.sciencedirect.com/science/article/ pii/001600329090001Y

[36] F. Shoji, "Comments on simplification of large linear systems using a two-step iterative method: A twostep projection algorithm," Journal of the Franklin Institute, vol. 313, no. 5, pp. 267 - 271, 1982. [Online]. Available: http://www.sciencedirect.com/ science/article/pii/0016003282900023

[37] G. Parmar, S. Mukherjee, and R. Prasad, "System reduction using factor division algorithm and eigen spectrum analysis," Applied Mathematical Modelling, 
vol. 31 , no. 11 , pp. $2542-2552,2007$. [Online]. Available: http://www.sciencedirect.com/science/article/ pii/S0307904X06002411

[38] V. P. Singh, P. Chaubey, and D. Chandra, "Model order reduction of continuous time systems using pole clustering and chebyshev polynomials," in Students Conference on Engineering and Systems (SCES-12), 2012, pp. 1-4. [Online]. Available: http://dx.doi.org/ $10.1109 /$ sces.2012.6199028

[39] S. K. Agrawal, D. Chandra, and I. A. Khan, "Order reduction of linear system using clustering, integral square minimization and dominant pole technique," International Journal of Engineering and Technology, vol. 3, no. 1, pp. 64-67, 2011. [Online]. Available: http://dx.doi.org/10.7763/IJET.2011.V3.201

[40] C. B. Vishwakarma and R. Prasad, "Clustering method for reducing order of linear system using pade approximation," IETE Journal of Research, vol. 54, no. 5, pp. 326-330, 2008. [Online]. Available: http://www. tandfonline.com/doi/abs/10.4103/0377-2063.48531

[41] S. Panda, J. S. Yadav, N. P. Patidar, and C. Ardil, "Evolutionary techniques for model order reduction of large scale linear systems," International Journal of Applied Science, Engineering and Technology, vol. 5, no. 1, pp. 22-28, 2009.

[42] S. Panda, S. K. Tomar, R. Prasad, and C. Ardil, "Reduction of linear time-invariant systems using routhapproximation and pso," International Journal of Electrical, Robotics, Electronics and Communications Engineering, vol. 3, no. 9, pp. 20-27, 2009.

[43] L. A. Aguirre, "The least squares pad method for model reduction," International Journal of Systems Science, vol. 23, no. 10, pp. 1559-1570, 1992. [Online]. Available: http://dx.doi.org/10.1080/00207729208949408
[44] J. Bansal, H. Sharma, and K. Arya, "Model order reduction of single input single output systems using artificial bee colony optimization algorithm," in Nature Inspired Cooperative Strategies for Optimization (NICSO 2011), ser. Studies in Computational Intelligence, D. Pelta, N. Krasnogor, D. Dumitrescu, C. Chira, and R. Lung, Eds. Springer Berlin Heidelberg, 2011, vol. 387, pp. 85-100. [Online]. Available: http://dx.doi.org/10.1007/978-3-642-24094-2_6

[45] L. Aguirre, "Validation of reduced-order models for closed loop applications," in Control Applications, 1993., Second IEEE Conference on, Sep 1993, pp. 605-610 vol.2. [Online]. Available: http://dx.doi.org/ 10.1109/CCA.1993.348337

[46] S. Panda, S. K. Tomar, R. Prasad, and C. Ardil, "Model reduction of linear systems by conventional and evolutionary techniques," International Journal of Electrical, Robotics, Electronics and Communications Engineering, vol. 3, no. 11, pp. 29-34, 2009.

[47] J. S. Yadav, N. P. Patidar, J. Singhai, S. Panda, and C. Ardil, "A combined conventional and differential evolution method for model order reduction," International Journal of Electrical, Robotics, Electronics and Communications Engineering, vol. 5, no. 9, pp. 68-75, 2011.

[48] C. Hwang and J.-H. Hwang, "A new two-step iterative method for optimal reduction of linear siso systems," Journal of the Franklin Institute, vol. 333, no. 5, pp. 631-645, 1996.

[49] C. B. Vishwakarma and R. Prasad, "Mimo system reduction using modified pole clustering and genetic algorithm," Modelling and Simulation in Engineering, vol. 2009, 2009. [Online]. Available: http://dx.doi.org/ $10.1155 / 2009 / 540895$ 